This item was submitted to Loughborough's Research Repository by the author.

Items in Figshare are protected by copyright, with all rights reserved, unless otherwise indicated.

\title{
A diagnostic service tool using FMEA
}

PLEASE CITE THE PUBLISHED VERSION

http://dx.doi.org/10.1080/0951192X.2010.486007

PUBLISHER

(C) Taylor \& Francis

VERSION

AM (Accepted Manuscript)

LICENCE

CC BY-NC-ND 4.0

REPOSITORY RECORD

Case, Keith, Amin Nor, and Ping C. Teoh. 2019. "A Diagnostic Service Tool Using FMEA". figshare. https://hdl.handle.net/2134/11040. 
This item was submitted to Loughborough's Institutional Repository (https://dspace.lboro.ac.uk/) by the author and is made available under the following Creative Commons Licence conditions.

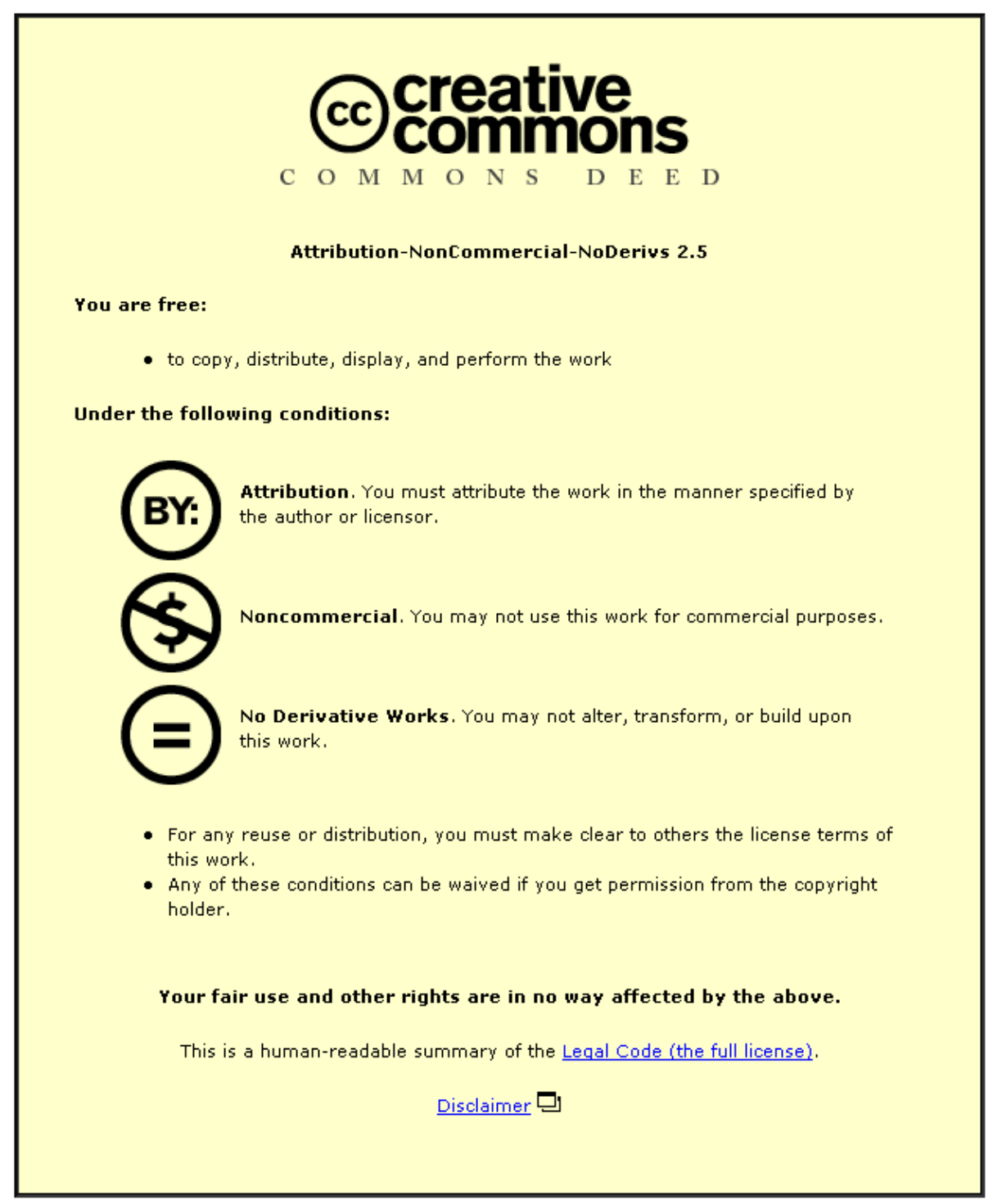

For the full text of this licence, please go to: http://creativecommons.org/licenses/by-nc-nd/2.5/ 


\title{
A Diagnostic Service Tool using FMEA
}

\author{
Keith Case ${ }^{1}$, Amin Nor ${ }^{2}$ and Ping Chow Teoh ${ }^{3}$ \\ ${ }^{1}$ Mechanical and Manufacturing Engineering, Loughborough University, \\ Loughborough, UK \\ ${ }^{2}$ University Kuala Lumpur - Malaysia France Institute, Kuala Lumpur, Malaysia \\ ${ }^{3}$ Motorola, Malaysia
}

Professor Keith Case, Mechanical and Manufacturing Engineering, Loughborough University, Loughborough, Leics, LE11 3TU

\begin{abstract}
The use of Failure Modes and Effects Analysis (FMEA) as the basis for a Diagnostic Service Tool (DST) is discussed in the context of Design for Service. Designers are assisted in developing diagnostic service tools early in the design process rather than this being a post-production activity. A system for computerised interactive FMEA generation from FMEA elements has been created by enhancing an existing object-oriented FMEA model to generate the FMEA elements and Diagnostic FMEA. The use of an object-oriented FMEA environment and FMEA object libraries promotes the reuse of information and increases data availability for diagnostic tool development. The Diagnostic Service Tool (DST) uses existing failure mode data to determine further characteristics of the failure of parts. The prototype software has been evaluated in a field service application using four automatic transmission problem cases. There was significant difference in repair times between the use of conventional repair manuals and DST. The research has demonstrated that the prototype software is successful in providing effective field service tools and suggests a method of providing feedback to the designer. In this way knowledge sharing between engineering and field service can be continuous and provide a significant improvement in product development. The approach has validity across many domains but has so far only been evaluated in the context of automotive systems and in particular automatic transmissions. Application in other areas would require substantial efforts in knowledge acquisition but the same general methods would be used.
\end{abstract}

KEYWORDS: FMEA, Diagnostics, Functional Model, Structural Model

\section{Introduction}

A fundamental shift is occurring in manufacturing companies away from selling products to providing services, so that for example Rolls-Royce are selling power over a period of years to the airline rather than selling an engine (Harrison, 2006). This introduces a Design for Service (DFS) concept that considers product 
serviceability issues at the very early stages of product design. The ability to isolate difficulties in maintenance, diagnosis and to recommend areas of improvement during the conceptual stages will lead to a more efficient failure isolation process. The integration of design and maintenance will encourage sharing of knowledge from the latter stages of the product life-cycle with those involved in the earlier phases. The product support and maintenance needs of systems are more or less decided during the design phase and designers are required to consult existing maintenance information from similar products (Blanchard, 2001). The collected maintenance records can be effectively re-used for the development of a new generation of products and reduce demands on service and maintenance (Markeset and Kumar, 2003).

Diagnostics systems have the goal of determining the causes of observed malfunction symptoms through reasoning and observation. One area of significant opportunity is to integrate design and service information and re-use Failure Modes and Effects Analysis (FMEA) information in the construction of diagnostic systems (Barkai, 2001). The model-theoretic approaches by Price et al (1995) and more general approaches (Barkai, 1998) have reported success in re-directing FMEA information at diagnostic tool applications. Several prototype systems have demonstrated that there are principled solutions to the diagnostic problems in certain application areas (e.g. Chen and Patton, 1999). However, most systems remain isolated programs that are not integrated with the work processes and many have been developed from a maintenance rather than a design perspective.

Price and Taylor (1997) describe the advantages that automated FMEA provides for diagnosis and describe its use for generating failure trees from FMEA reports. Similarly the value of re-using FMEA information in diagnostic systems to integrate design and service information across supply chains has been demonstrated (Barkai, 2001). Price (1997, 2000) in his AutoSteve system has shown that automated generation of FMEA is applicable in analysing automobile electrical circuits for 
diagnostic purposes. Barkai (1998) also showed that FMEA information is able to generate an expert system for diagnosis. The work by Teoh (2003) shifted the FMEA generation into the conceptual design stage. The method of deploying structural modelling, functional modelling and reasoning techniques was able to generate process and design FMEA based on limited information (Hunt at al, 1995, Russomanno et al, 1993). Exploiting these methods and the use of FMEA generation for developing diagnostic models encourages knowledge reuse and sharing. Hence this will provide a method of addressing serviceability issues at the very early stages of product design.

The main aim of this research was to show the potential for improving product maintainability and serviceability by integrating the design and diagnostic tasks. The method of achieving this was to (i) establish an FMEA model based on previous research in functional and structural modelling for diagnostic failure data generation, (ii) generate diagnostic failure data from automated FMEA software, (iii) build a prototype Diagnostic Service Tool based on the generated diagnostic data and field service information and (iv) evaluate the proposed Diagnostic Service Tool in troubleshooting actual failures.

\section{Failure Modes and Effects Analysis}

Failure Modes and Effects Analysis (FMEA) is widely used for the early stages of system development. FMEA has been widely standardised, (e.g. as BS 5760, 1991, MIL-STD-1629, 1980), and has been extensively used for safety and reliability analysis of products and processes particularly in aerospace, nuclear and automotive industries (Ebeling, 2000). FMEA is a methodology to determine all potential failure modes, the effects these failures and how to deal with the failures based on severity 
and probability of occurrence. FMEA has frequently been reviewed (e.g. Bouti and Ait Kadi, 1994).

Several researchers have used FMEA in design and production process applications. Hsiao (2002) applied both Quality Function Deployment (QFD) and FMEA in a new product development process. Linton (2003) showed the use of process mapping and FMEA for the design of services and process in e-commerce. Davidson and Labib (2003) integrated a modified FMEA into an analytic hierarchical process for design improvement. Parkinson and Thompson (2004) presented the use of FMEA in the planning and execution of product remanufacture.

In automotive industries FMEA is specified as a part of the quality system in QS-9000 which is an automotive version of ISO-9000 (QSA, 1998; AIAG, 1998). Automotive original equipment manufacturers (OEMs) use FMEA and require their suppliers to submit FMEA as part of product approval documentation (Dale and Shaw, 1990; Ford Motor Company, 1989; AIAG, 1995; SAE, 2002). Commercial FMEA software provides clerical tools for developing and maintaining FMEA documents but this can still be tedious. Automation of the process should help, but automation of the reasoning is not simple.

\section{Diagnosis}

Diagnosis may be considered as the process of Failure Detection, Isolation and Recovery (Frank 1993). Failure detection and isolation techniques are normally model or knowledge techniques (Patton, Frank and Clark, 2000). A common way to represent diagnostic tasks is to divide them into two tasks (Krysander, 2003). The first is to detect the symptoms and the second is to determine which failure has occurred. Price (2000) describes troubleshooting procedures that are already in a format 
understandable to engineers, but in field service the diagnostic logic tree, commonly known as the diagnostic tree, is much preferred.

A study conducted by the Service Technician Society of SAE reports that 53\% of the surveyed technicians indicated that they do not have sufficient resources to maintain vehicles (Barkai, 2001). Of those, 50\% indicated that the most critical resource is information, whereas only $14 \%$ required additional tools.

Early efforts were made by Price et al (1995) in the Flame system to link FMEA and diagnostics. Despite this effort, one of the challenges in utilising FMEA for field diagnosis is that it deals primarily with design documents, conceptual models, early prototypes and focuses on design artifacts (Price, 2000). FMEA assumes that, under ideal circumstances, all failure modes are addressed and fully rectified during the design and engineering phases. Field diagnosis deals not only with design inadequacies, but also with physical variations and natural mortality (a product reaching the end of its design life). However, the work by Barkai (1998) has shown that the results of the FMEA can be used to develop and produce an efficient diagnostic system. Proton Car Service Centres use diagnostic tools that are typical of the industry and they are focussed mainly on failure diagnosis or detection and not effectively on failure isolation. This is because the diagnostic tools do not provide the actual repair procedures for the detected failure. The current tools available to car manufacturers are unable to isolate most of the detected failures. In 2005 one manufacturer ceased production of a car model due to numerous customer complaints, especially concerning the automatic transmission system. Hence, a supportive diagnostic service tool is urgently needed and it should be able to support the service technician in diagnosing, isolating and repairing the failure. 


\section{Modelling}

A model-based approach to diagnosis has advantages including the synthesis of unforeseen failures, re-use through modularity, use of system specifications and design as input knowledge for the diagnostic engine and explanations of the failures (Chittarro and Ranon, 2004).

A functional model can be used to verify the performance of the design and since it describes the intended function of a system, it enables engineers to evaluate designs early in the development process. The functional model consists of two main components: function and behaviour. The function of a system provides the design intent, whereas the behaviour describes how the structure of an artifact achieves its function (Gero et al, 1991 and Russomanno et al, 1993).

A structural model is defined as "the components that make up an artifact and their relationships” (Gero et al, 1991) and contains information on all the components, entities, sub-processes or sub-systems, and the interactions among them. Generic functions originated from engineering design methodologies (Pahl and Beitz, 1996) and Hirtz et al (2001) developed a comprehensive list covering a wide range of applications in design and manufacturing. Teoh (2003) in his work adapted the Hirtz functional basis in order to develop the generic functions required in his case studies as shown in table 1 .

\section{The FMEA Model}

The FMEA Generation (FMAG) software created by Teoh (2003) has been selected to generate the required FMEA information, but an FMEA model for a specific product design has to be built.

An object-oriented approach, causal reasoning and Unified Modelling Language (UML) diagrams have been used for the FMEA modelling. The FMEA Model is adopted from a technique known as the transformation system as proposed 
by Hubka and Eder (1988) which basically transforms an operand at the input to a desired state at output. Then component libraries, function units, functional diagrams and cause and effect propagation are created. A causal reasoning technique adapted from the "knowledge fragment" reasoning approach of Kato et al (2002) is used. The knowledge is divided into precondition and postcondition in the form of "operator failure state" and "operand failure state”. The FMEA model forms the framework for knowledge collection and organization in order for FMEA generation to take place.

The modelling is illustrated using an automatic transmission powertrain with the objective of developing a Diagnostic Service Tool application for the motor industry. In order to function as a complete transmission system, the power train is connected to other mechanical systems, hydraulic systems and electrical systems which control and provide the input and output. Briefly, engine torque is transferred to the torque converter through the drive plate, which is attached to the engine crankshaft. Torque, which has been transferred to turbine vanes in the torque converter through the medium of Automatic Transmission Fluid is then transferred through the input shaft to the rear clutch retainer or the multi-plate clutch. It is then carried through the sun gear (forward and reverse sun gear) and the annulus gear in the planetary gear set to the transfer shaft. It is delivered through the transfer shaft and the differential drive gear to drive the $\mathrm{CV}$-joint by the differential assembly and finally the wheels. Figure 1 shows a sectional view of an automatic transmission system and the power train components.

A transformation system consists of technical system, technical process, human system and active environment. The effects are produced by the acting operators, by means of action processes and action chains within the operators that transform the inputs of the operators into their outputs (Hubka and Eder (1988)). In 
this case, the power train system is represented by the important components: torque converter, input shaft, sun gear, planetary gear set and transfer shaft. The engine torque is the operand of the process. The technical process consists of the process steps the engine torque has to go through in order to achieve the required gear ratio. (figure 2).

In order to achieve different gear positions, the input torque has to undergo different technical processes. For example, in first gear the rear clutch is actuated and the input shaft is connected to the forward sun gear. The torque is conveyed to the forward sun gear which rotates in the clockwise direction. The torque is then conveyed from the forward sun gear through the short pinion (counterclockwise) and the long pinion (clockwise) to the annulus gear (clockwise) to achieve the reduction ratio of the forward 1st gear. The one-way clutch locks the annulus gear from rotating anti-clockwise. The operating elements are the rear clutch and one-way clutch.

The component library is created using the class hierarchy structure (Figure 3) and an assembly tree hierarchical structure.

In FMAG, the transformation system is used to organise the entities in the component library. The entities are organised into five classes of technical system, technical process, human system, active environment and the operand to define the transformation system.

The technical system in a transmission system is represented by a machine and its components that are involved to run the process. The technical process is represented by its process and process steps in order to achieve its output. An object diagram is created by incorporating the class diagram for the power train system into the transformation system as shown in figure 4 . 
The interactions among the entities in the transformation system are used to achieve the design objectives and are represented in a conceptual model. The interaction is illustrated by a functional unit in the transformation diagram. In the power train system example, the input shaft interacts with the sun gear through the function "convey". The input shaft is the entity known as the operator which in turns acts on another entity, the sun gear. The word 'conveys' in this case is a generic function term to represent the move action. The sun gear which is the receiver of the action 'conveys' is known as the operand of the relationship. This relationship among the operator, an operand and a generic function is known as a function unit.

Since operator and operand are sub-classes of entity, an operator in one situation can become an operand in another. The sun gear is an operand in the function unit, "input shaft conveys sun gear” but it can be an operator for a new function unit "sun gear conveys torque". The remainder of the functional units for the power train system can be derived to form a functional diagram from the transformation system.

The FMEA Model proposed by Teoh (2003), utilizes a cause and effect propagation method to simulate the actual behaviour of a design in the real world. A state change in one entity of a functional model will affect the status of the interrelated entities. In the power train system, the engine torque that has been conveyed by the torque converter will be conveyed to the sun gear through the input shaft by the action of the clutches and brakes. The clutches and brakes will have a state change from "not activating” to "activating". This state of change will trigger a change to the input shaft from "not conveying” to "conveying” and in turn trigger a change to the sun gear from "not conveying” to "conveying” and so forth until the final gear ratio output. The action to convey the torque is the cause that triggers the changes across 
the components in the model. Hence, the model is said to use a cause and effect propagation.

Similar to FMAG, in DIFMAG (Diagnostic FMEA Generation) the failure causes that create the failure modes of a model are the particularly interesting information used to generate the DIAgnostic FMEA (DIFMEA). This propagation is carried out through the behaviour of a generic function. The relation between an entity state and a function behaviour is then characterized into precondition and postcondition. The state of the operator will determine the behaviour of the generic function within a function unit. The behaviour will in turn decide the state of the operand within the function unit. These differentiate between the precondition and post condition. Based on this approach, the relationship is as shown in figure 5.

In most cases, the operand of the function unit is an operator of the next function unit. Any state changes will propagate until the last boundary of the system. The series of preconditions and postconditions creates a causal change for a particular state change event. The preconditions and postconditions gain knowledge fragments through historical data extracted from failure reports and the FMEA. For a particular function unit, the operator state and the behaviour of a failure event form a set of preconditions. The behaviour and the state of the operand form the postcondition of the same event. The failure cause and effect is defined by the operator and operand states of a function unit, while the failure mode is defined by failure behaviour of the generic function. The knowledge fragment captured in precondition and post condition can be arranged as shown in tables 2 and 3 .

The precondition defines the behaviour of the torque converter when it is not transferring torque and the behaviour of the clutches and brakes when not conveying. The postcondition provides the knowledge about the response of the input shaft and 
torque when it receives the behaviour "not transferring" and "not conveying" from the operator that should make the input shaft and the clutches and brakes move.

This discussion has been concerned with the development of an FMEA model for a power train system based on the FMAG requirements, an approach to enable automated FMEA generation. The use of the "knowledge fragment” reasoning approach has two advantages. First the proposed reasoning technique forms a framework for knowledge collection, organisation and reuse. Second, by using this approach, the static knowledge is confined to the entities and their functions, but not to the function units. During the reasoning process, it is possible to create new knowledge by matching the precondition and postcondition knowledge with similar failure behaviour. Hence this approach has led to the idea of new knowledge generation based on minimum information.

\section{Diagnostic FMEA Generation}

Diagnostic FMEA Generation (DIFMAG) is an elaboration of FMAG in order to generate Diagnostic FMEA (DIFMEA) information that is further used to generate the Diagnostic Service Tools (DST) (Nor, 2006). FMAG allows users to perform several tasks using the FMEA Model including the creation and storage of object, function and model data in a permanent library for future reuse and the formation of a cause and effect chain (Teoh, 2003). The additional requirements for DIFMAG include DIFMEA generation by the creation of diagnostic trees using the information in the FMEA model with the corresponding symptoms and effects from cause and effect chains.

The three tier design of the FMAG software has been adapted and expanded to form the basic structure of DIFMAG. The inner tier is the FMEA and diagnostic database. The FMEA database consists of relational tables that are constructed based 
on the FMEA model. The diagnostic database consists of a relational database for the construction of a diagnostic tree and a diagnostic service tool. The middle tier deals with modules responsible for calling data from the database which mainly uses Structured Query Language (SQL) and logic. The outer tier consists of Visual Basic form objects which cater for the user interfaces.

\section{DIFMEA Generation Process}

The DIFMEA generation process is based on FMAG. A functional diagram is used to represent the product based on conceptual modelling through (a) functional analysis, (b) controls and mechanism, (c) component selection, (d) mapping of components to controls and (e) combining function units into a functional diagram.

The functional analysis starts with function or process decomposition from a high-level function statement. For the power train system, the working elements are "to transfer the engine torque from the input shaft to different sets of gears to achieve the various final gear ratio outputs”. The design also requires the gears to lock and unlock to achieve different gear positions. In order to achieve the "lock and unlock different gears” there is a need to introduce another sub-function concerned with brakes and clutches. The resulting possible functions are, input torque, activate clutches and brakes, generate motion, lock and unlock gears, transfer torque and output torque.

The controls and mechanism are determined by the enabling transferring process. In this case the planetary gear sets, annulus gear and the transfer gear will provide controls to the torque transferring process. These controls and mechanism are represented in an IDEF3 diagram (Mayer et al., 1995).

Identification of the basic components is done with reference to the processes going on within the torque transferring process. Structural decomposition is used 
where the total system is decomposed into smaller sub-systems or components until a level where some of the components can be mapped onto the decomposed functions. The mechanism and controls will provide a guide to the level of structural decomposition. A decision can be made on whether to consider all components or just those which are more likely to be involved in the FMEA. As an example for an automatic transmission torque transferring process only certain components were selected for simplicity (principally those annotated in Figure 1).

The next step is to verify whether the selected components can be established in an object class. For example, the entities "front clutch", "end clutch" and "one-way clutch" may be generalized into a "clutch" entity. The objective is to specify the component as specifically as possible while considering the value the component may have in the object library for reuse. Figure 6 shows the structural decomposition chosen for the power train system.

This next step is the mapping of the selected components to the mechanism and controls. This is to establish the interactions for components corresponding to the functions. For example, to realise the function activate clutch, the function units piston - actuates - clutch plates and clutch plate - activates clutch are created. Thus by mapping onto the structural components, the IDEF3 preliminary functional diagram is created as shown in figure 7.

The next step is the combination of the function units into a functional diagram. For example, in the case of the automatic transmission, the various gear ratios are represented by six different scenarios. As an example, in order to achieve the gear ratio in 1st gear, the rear clutch and one-way clutch are actuated. The oneway clutch locks the annulus gear preventing anticlockwise rotation. The driving force is transmitted to the forward sun gear which rotates in the clockwise direction. 
Hence, torque is conveyed from the forward sun gear through the short pinion (counterclockwise) and the long pinion (clockwise) to the annulus gear (clockwise) to achieve the reduction ratio of the 1st gear (Figure 8).

The functional basis developed for the DIFMAG application is based on the original work of Hirtz et al (2001) and Teoh (2003), and the function selection is carried out in parallel with object formation which is based on the created conceptual model. According to Teoh (2003), it is important that standard terms are used within a design group or organization because the functions will be used as a key to retrieve FMEA data at a later stage. A list of the functional basis for function selection that is developed for DIFMEA generation process is as shown in figure 9.

In the DIFMAG application, the cause and effect building is based on the field failure report which is channeled into the FMEA database. The typical attributes captured in a failure report are the failures, the causes of failure and the solutions to the failures. The generated FMEA acts as a guide to the actual product failures and is the basis for DST development. Subsequently, this information will provide designers with information to decide on the alternatives in design and components.

This is the final process that will produce the DIFMEA information for the development of the DST. DIFMEA generation can be made from any components in the object library and be saved as a separate report.

\section{Diagnostic Service Tool}

The DIFMAG software was used as the basis of a Diagnostic Service Tool (DST) prototype model. The identification of users' needs and the establishment of requirements were addressed using the lifecycle interaction design model by Preece et al. (2002). The aim was to understand as much as possible about the users and produce a stable set of requirements from the needs identified. A structured interview 
was carried out with a small group of automatic transmission technicians and the users of diagnostic tools on the subject of how they retrieve and perform repair procedures.

Eight automatic transmission technicians from the Transmission Expert Centre, Malaysia were selected for the study. All participants regularly used diagnostic tools and repair manuals for problems related to engine and transmission systems. In the interview sessions, each was asked about their current practice and problems and they gave their opinions on how they solve the transmission problems which are not detected by the existing diagnostic tools. The structured interview schedule was divided into three sections. The first elicited the respondent's background knowledge on using diagnostic tools and computers. The second focused on automatic transmission repair experiences and the third focused on their current practice in solving the transmission problems.

A low fidelity prototype, which was based on task descriptions elicited by the interviews, was used for the initial design and requirements for interaction, diagnostic tree development, problem cases and repair procedures design. Three automatic transmission experts and trainers participated in the low fidelity prototype informal evaluation. Each of them went through all the tasks for the troubleshooting system cases, diagnostic tree, transmission information and repair procedure in detail. After completing the tasks, they were asked to give feedback related to the content, structure and screen design of the system through a structured interview.

The main purpose of the evaluation was to verify the DST methodology and prototype implementation. Three different levels of automatic transmission technician were identified from the recruitment questionnaire, none of whom had taken part in any previous related test. Three subjects participated in a pilot study. All were 
diagnostic tools users and had experience in automatic transmission repairs and evaluating a variety of diagnostic tools software related services. Several changes were made to screen design, evaluation and procedures based on observation and feedback.

The DST has general limited information on part failures, but the user can specify extended symptoms in the form of Yes/No Questions to further pin-point a specific part failure. As a result, a tool is created in the form of a practical diagnostic service tool.

DST acquires information from the FMEA database for part failure information. This is used by both the "Diagnostic Tree Tool" and the "Diagnostic Tree Wizard” module (figure 10).

Before DST can be utilised, information on parts failure has to be built. This can be done by using the Diagnostic Tree Tool (DTT) which collects information from the DIFMEA database. The user can select any related object to specify the detailed problem. DTT will create additional characteristics of the part failure with Yes/No questions, specify the recommended action, and create a link to the repair procedure information.

There are two database tables created for the DTT process. The Diagnostic Tree holds information on questions, their answers, linkages, corresponding procedure and question reference, while the Tree Reference keeps references to created parts including Model, Part Names and Symptoms. The repair information module enables the creation of repair procedures for specific items having corresponding problems to assist DST users in selecting the proper action on the specified failure. The repair information contains a list of repair procedures that can be linked with the DST. The components in the repair procedure include the symptoms, causes of failure and repair 
procedures. The repair procedure displayed for "No Forward Gear" is shown in figure 11. The repair actions suggested come directly from real field service information gathered for this research.

All the data on repair information is stored in the Repair Procedure table, and can be retrieved and modified by users.

To assist the user in specifying parts failure with corresponding symptoms, DST gives options for users to select either from the pre-set symptoms available in the symptom list or to manually specify their parts and symptoms using the Problem specifying form. Once the Parts failure information has been built using DTT and linked to Repair information if available, the DST can be used.

If the user chooses to specify combinations of parts and symptoms manually, the system will search for the availability of corresponding information in the database. DST will prompt the user if the information is not available. Otherwise, it will start the question and answer process. The purpose of having yes/no questions is to determine the exact problems related to the specified symptoms. The information in the FMEA database for the part failure (e.g. cause, symptoms) are limited and often rather general. Some symptoms shown may have been caused by several different types of parts/ component failure. In this case, DST will help to determine the corresponding cause by further elaborating failure symptoms in the form of questions and answers.

\section{Evaluation}

Following the initial pilot studies, a main evaluation was conducted to verify the DST methodology and validate the prototype application. The evaluations were based on real automatic transmission problems that arose at the Proton service and repair centre in Malaysia and were carried out in two stages. The first stage was carried out 
theoretically to determine that the DST methodology and framework in solving the transmission problems was comparable to the available manuals. Four major problem cases were selected for the evaluations, as this was considered sufficient to represent the problems with the KM series automatic transmissions. The second stage evaluation was carried out practically by technicians involved in servicing and repairing transmissions so as to validate the prototype DST in solving real practical situations.

The first evaluation is to determine whether technicians with various skills can diagnose and repair correctly either by using the manuals or DST. The evaluation was based on determining the Hit Rate of the two methods (hit rate as defined as the percentage of problem cases correctly diagnosed and repaired (Barkai, 1998)). The second stage evaluation compared the times taken to complete the given tasks for both methods.

In total 69 students undertaking the Diploma in Automotive Maintenance from the University of Kuala Lumpur participated in the evaluation. These students were given one year's exemption from a three year course due to their working experience and had already passed at least Malaysian Skills Certificate Level 2 and Institute of Motor Industry United Kingdom (IMI) Certificate Level 1. The four major KM series transmission problems earlier identified were used for the evaluation and were (1) No Forward and Reverse Gear, (2) No Forward Gear, (3) No Reverse Gear and (4) No Fourth Gear.

A double-blind method was used to determine the Hit Rate or the percentage of problem cases correctly diagnosed and repaired by the technicians from diagnostic sessions, and two sessions were carried out for each technician level. 
In general the technicians were required to determine the possible causes of each of the transmission failures, extract the troubleshooting procedure process to examine the problem and explain briefly the required action to rectify, repair or replace any faulty parts and components.

In the first session they were asked to diagnose and suggest repair action using repair manuals and documentation. For the following session they performed the same task by utilizing the DST only. They were given a short briefing regarding the DST and ample time to complete the tasks. Initially, they were also given time to read the DST user manual and allowed to browse through the system.

In order to meet the objective the test was conducted to determine the ability of each level to diagnose and suggest repair actions correctly for all the four transmission problems cases by using the repair manuals. Each level was given sets of questions to answer. The possible causes of the problems could be initially determined by referring to functional data of a power train system and information on the usage of transmission element for each gear position. In this way a simple diagnostic tree could be drawn.

\subsection{Stage 1 Evaluation: Hit Rate using DST}

The aim of this evaluation was to test the ability of the technicians to diagnose and suggest repair actions by using the DST prototype. The technicians of the three levels were given the second task after all had completed the first task. They were given the user guide and DST software window readily available on the computer screen workstation. By browsing the DST, a list of existing symptoms can be selected from the database. The related problem is then selected and the causes analysed in detail according to the instructions as shown in figure 12 until the recommended actions are 
presented. The repair procedure and action can be selected for each of the possible causes from the list of repair information.

\subsection{Stage 2 Evaluation: Repair Cycle Time}

The evaluation was conducted in an actual automatic transmission training and repair shop. A total of 18 selected technicians with working experience in automatic transmission service and repair comprising 6 from each skill level participated in this evaluation. The main aim was to determine the total repair time taken by each level for both repair approaches.

Two sessions were carried out for this stage for each problem case with a total of 8 sessions. For the first session the subjects were required to diagnose and repair using the manuals and for the second session the DST prototype was used. The transmissions were prepared by creating different causes contributing to each of the problems. Each technician was given a complete transmission on a working bench, a repair toolbox. and a set of instructions for each problem case. The main task was divided into five smaller tasks in order to complete each problem case. The times for each smaller task were recorded in order to determine the time breakdown for the whole task. The task breakdown for all the case studies includes the diagnosis of the causes of the problem, dismantling the transmission and analysis of the symptoms, replacement of the affected parts and the re-assembly of the transmission.

The evaluation was conducted to determine the total repair time taken to complete all the repair work by referring to the repair manuals. Each subject was involved in a total of 4 sessions to complete the evaluations. In order to initiate the repair, the participants were expected to refer to the repair manuals to determine the specification of the transmission. 
By looking at the working elements and the power flow system the possible components causing the related problems can be detected. Analysis of each of the causes is carried out and a trouble shooting guide or diagnostic tree is drawn to determine the causes and possible repair actions.

Verbal explanation of the possible causes was given to the examiner before proceeding to the next task. The transmission was then disassembled and the possible problem component inspected to determine the actual causes. The required repair action or parts replacement was then carried out and the transmission reassembled. Special attention was given to the use of special tools and the tightening torque. The total time to perform each task was recorded.

\subsubsection{Repair Time using DST}

These tasks are similar to the first task but are carried out by referring to the DST prototype software. The causes of problems are directly referred to the existing symptoms available in the software. Analysis could be done for every cause by following the instructions. The recommended action and repair procedure could then be identified. The transmission was disassembled and inspected according to the diagnostic tree instructions. The main causes identified were repaired and the transmission reassembled. The time for each of the tasks breakdown was recorded.

\subsection{Evaluation Results}

The results of all four evaluations of stage 1 and 2 answer sheets were collected and the repair time compiled. The final results were then evaluated and approved by two transmission experts from Proton and Hyundai Motors Malaysia.

\subsubsection{Stage 1 Evaluation Result}

There were 51 student technicians in 3 groups participating in the first stage. The first group consisted of 21 students at level 1 who achieved an average hit rate of $29.8 \%$ 
using manual methods and $81.0 \%$ using the DST. The second group consisted 19 level 2 students and the respective hit rates were $60.5 \%$ and $93.4 \%$. The third group consisted of 11 part-time students who are full-time working technicians in service and repair centres and their hit rates were $84.1 \%$ and $97.7 \%$ respectively. Average hit rate using the DST was significantly better than using just the technical repair manuals. DST presented the technician with a focused and precise course of action and also resulted in a reduction in false part replacements. On the other hand, the technicians had to devise a troubleshooting strategy independently by using the repair manuals.

\subsubsection{Stage 2 Evaluation Result}

There were 18 selected technicians from 3 groups participating in this stage. Each group consisted of 6 technicians participating in each case study. In all the evaluations, the time taken to complete the task decreases as the technician level increases. However, in all cases the overall repair time improved by utilising DST when compared with the repair manuals. Average time improvement was $17.9 \%$ for level 1, 10.7\% for level 2 and 5.0\% for level 3.

\section{Conclusions}

The evaluations have demonstrated the DST's capability of assisting in the repair of four major problems of KM series automatic transmission. They have also shown that the repair time has improved by utilising the prototype DST as compared to the repair manuals. The most noticeable time improvement is the diagnosis time which has shortened by $60.5 \%$. on average for all cases.

The parts repair procedure and reported transmission problems database will grow with time. Hence experience from the technician knowledge will be gathered and documented. This precious knowledge can then be used by junior technicians as a 
reference and for training purposes. Thus it will allow immediate reuse of information not only by the repair technicians but by the designer as well. Designers can directly reuse this actual failure knowledge to improve existing product design or for a new design.

Another significant advantage is that this field failure information can be reused to improve the accuracy of the FMEA and lower the costs of keeping the data updated, thus allowing knowledge sharing between the two activities. Hence the objectives of bridging the gap between the engineering and field service can be met.

\section{References}

AIAG Automotive Industry Action Group, 1995. Potential Failure Mode and Effects Analysis (FMEA) Reference Manual, 2nd ed., AIAG, Southfield, MI, USA.

AIAG Automotive Industry Action Group, 1998. Quality Systems Requirements: QS9000, 3rd ed., AIAG, Southfield, MI, USA.

Barkai, J. (1998). Automatic Generation of a Diagnostic Expert System from Failure Modes and Effects Analysis (FMEA) Information, SAE Paper 99MF-24.

Barkai, J., 2001.Vehicle Diagnostics - Are You Ready for the Challenge? Proc. Automotive and Transportation Congress and Exposition, ATTCE 2001, Barcelona, Spain, Vol 5, Society of Automotive Engineers, USA.

Blanchard, B.S., 2001. "Maintenance and support: a critical element in the system life cycle”, Proc. Int. Con. of Maintenance Societies, May, Melbourne, Paper 003.

Bouti, A.and Ait Kadi, D., 1994. "A state-of-the-art review of FMEA/FMECA". International Journal of Reliability, Quality and Safety Engineering. Vol 1, No. 4, 515-543.

BS 5760 Part 5, 1991. Reliability of systems, equipment and components. Guide to failure modes, effects and criticality analysis (FMEA and FMECA).

Chen, J. and Patton, R.J., 1999. "Robust model based fault diagnosis for dynamic systems”, Kluwer Academic Publishers, Boston, U.S.A.

Chittaro L. and Ranon R., 2004. Artificial Intelligence, Elsevier Science Publisher, 147-182.

Dale, B. and Shaw, P., 1990. "Failure modes and effects analysis in the UK motor industry: a state-of-art study", Quality and Reliability Engineering International, Vol. 6, 179-88.

Davidson, G. and Labib, A., 2003. "Learning from failures: design improvements using a multiple criteria decision-making process", Proc. Inst. of Mechanical Engineers, Part G: Journal of Aerospace Engineering, Vol. 217 No.4, 207216.

Ebeling, C., 2000. An Introduction to Reliability and Maintainability Engineering, Tata McGraw-Hill Company Ltd, New York, NY.

Ford Motor Company, 1989. Supplier Quality Improvement Guidelines for Production Parts, Ford Motor Company, Dearborn, MI. 
Frank, P. M., 1993. “Advances in observer-based fault diagnosis”. Proc. TOOLDIAG+93. CERT. Toulouse, France, 817-836.

Gero, J.S., Tham, K.W. and Lee, H.S., 1991. "Behaviour: A Link Between Functional and Structure in Design”. Proc. IFIP WG 5.2 Working Conference on Intelligent Computer Aided Design, Elsevier Science Publisher.

Harrison A, 2006. "Design for service - harmonizing product design with a services strategy”. Proc. of GT2006, ASME Turbo Expo 2006: Power for Land, Sea and Air, Barcelona, Spain.

Hirtz J., Stone B., McAdams A., Syzkman S. and Wood KL., 2001. “A Functional Basis for Engineering Design: Reconciling and Evolving Previous Efforts”. Research in Engineering Design 13(2), 65-82.

Hsiao, S., 2002. "Concurrent design method for developing a new product", Int. J of Industrial Ergonomics, Vol. 29, 41-55.

Hubka V. and Eder W.E., 1988. Theory of Technical System: A Total Concept Theory for Engineering Design, Springer-Verlag Berlin.

Hunt, J.E., Pugh, D.R. and Price, C.J., 1995. "Failure Mode Effects Analysis: a Practical Application of Functional Modelling”, Applied Artificial Intelligence, $\mathrm{Vol}$ 9, 1, 33-44.

Kato Y., Shirakawa T. and Hori K., 2002. "Utilizing Fault Cases for Supporting Fault Diagnosis Task”, in Proc $6^{\text {th }}$ Int Conf on Knowledge-Based Intelligent Information and Engineering Systems, Crema, Italy.

Krysander M., 2003. Design and Analysis of Diagnostic Systems Utilizing Structural Methods, PhD Thesis, University of Linkoping, Sweden.

Linton, J., 2003. "Facing the challenges of service automation: an enabler for ecommerce and productivity gain in traditional services", IEEE Transactions on Engineering Management, Vol. 50 No.4, November, 478-84.

Markeset, T. and Kumar, U., 2003. "Integration of RAMS information in design processes - a case study”, Proc. Annual Reliability and Maintainability Symposium, 376-392.

Meyer, R.J., Menzel, C.P., deWitte, P.S., Blinn, T. and Peraketh, B., 1995, Information Integration for Concurrent Engineering (IICE) IDEF3 Process Description Capture Method Report, Report No AL-TR-1995-XXXX, Logistics Research Division, Wright-Patterson AFB, OH, USA.

MIL-STD-1629, 1980. Procedures for Performing a Failure Mode, Effects and Criticality Analysis.

Nor, A.M., 2006. Design for Service: Integrating Product Design and Diagnostics. Doctoral Thesis, Loughborough University.

Pahl, Gn and Beitz, W., 1996. Engineering Design A Systematic Approach, Second Edition, Springer_Verlag London.

Parkinson, H. and Thompson, G., 2004. "Systematic approach to the planning and execution of product remanufacture", Proc. of the Institution of Mechanical Engineers, Part E: Journal of Process Mechanical Engineering, Vol. 218 No.1, 1-14.

Patton, R. J., Frank, P. M. and Clark, R., 2000. Issues of Failure Diagnosis for Dynamic Systems, (Springer, New York).

Preece, J., Rogers, Y. and Sharp, H., 2002. Interaction Design: Beyond HumanComputer Interaction. New York, John Wiley \& Sons.

Price C.J., 1997. AutoSteve: Automated Electrical Design Analysis, Department of Computer Science, University of Wales, Aberystwyth, UK. and First Earth Ltd, The Mill, Mill Street, UK 
Price C.J , Pugh D.R, Wilson M.S. and Snooke N.A., 1995. "The Flame system: Automating electrical failure mode and effects analysis (FMEA)", Proc. Annual Reliability and Maintainability Symposium, 90-95.

Price, C. J., 2000. “AutoSteve: Automated Electrical Design Analysis”, in Proc. ECAI-2000, 721-725, Berlin, August 2000.

Price C. J. and Taylor, N. S., 1997. "Multiple Failure Diagnosis Using FMEA”, in Proc. AAAI97/IAAI97 Conference, 1052-1057, Providence, Rhode Island.

QSA, 1998. Quality System Assessment, 2nd ed., DaimlerChrysler Corporation, Ford Motor Company, and General Motors Corporation, March.

Russomanno D.J., Bonnell RD. and Bowles J.B., 1993. "Functional reasoning in a failure modes and effects analysis (FMEA) expert-system”. Proc. Annual Reliability and Maintainability Symposium, 339-347.

SAE, 2002. Potential Failure Modes and Effects Analysis in Design (Design FMEA) and Potential Failure Mode and Effects Analysis in Manufacturing and Assembly Processes (Process FMEA) and Effects Analysis for Machinery (Machinery FMEA), SAE J-1739, SAE, Warrendale, PA, USA.

Teoh P.C., 2003. Failure Modes and Effects Analysis for Conceptual Design. Doctoral Thesis, Loughborough University, UK.

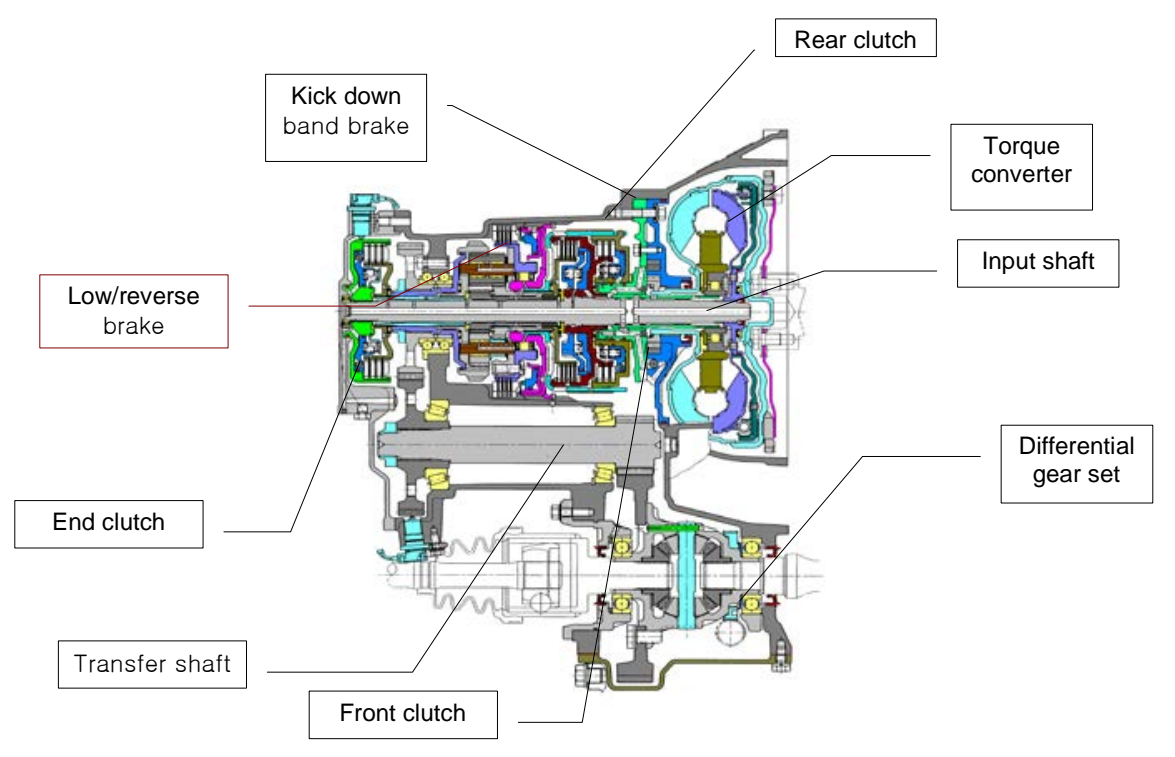

Figure 1. Sectional View of KM series Automatic Transmission 


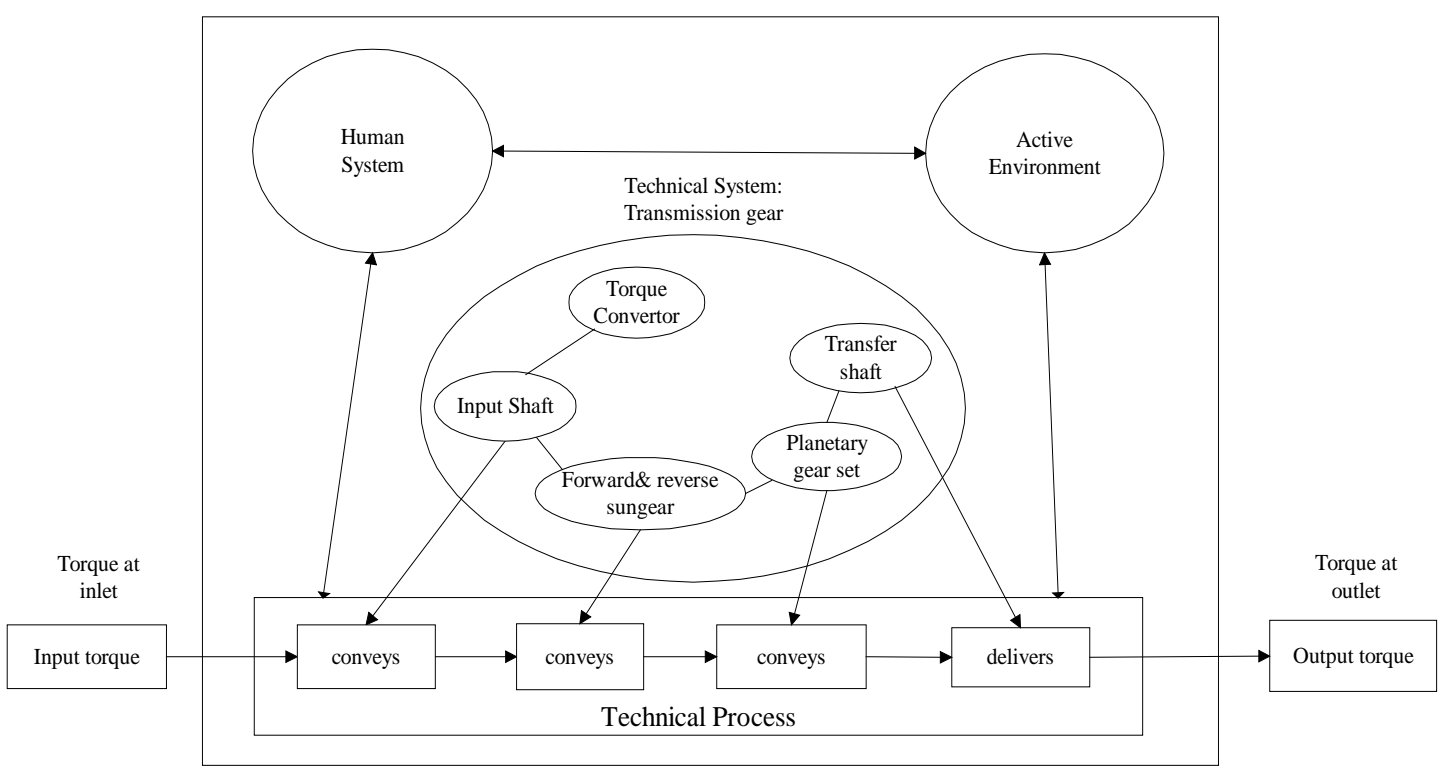

Figure 2. Transformation System for Power Train System 


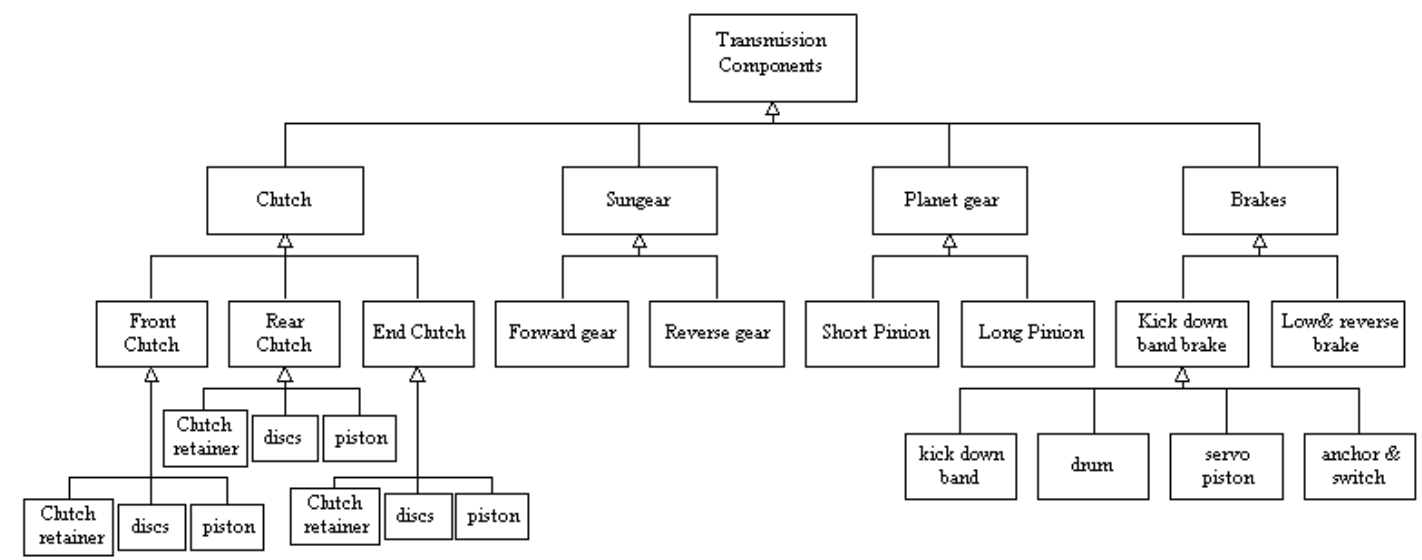

Figure 3. Class Hierarchy for Component Library 


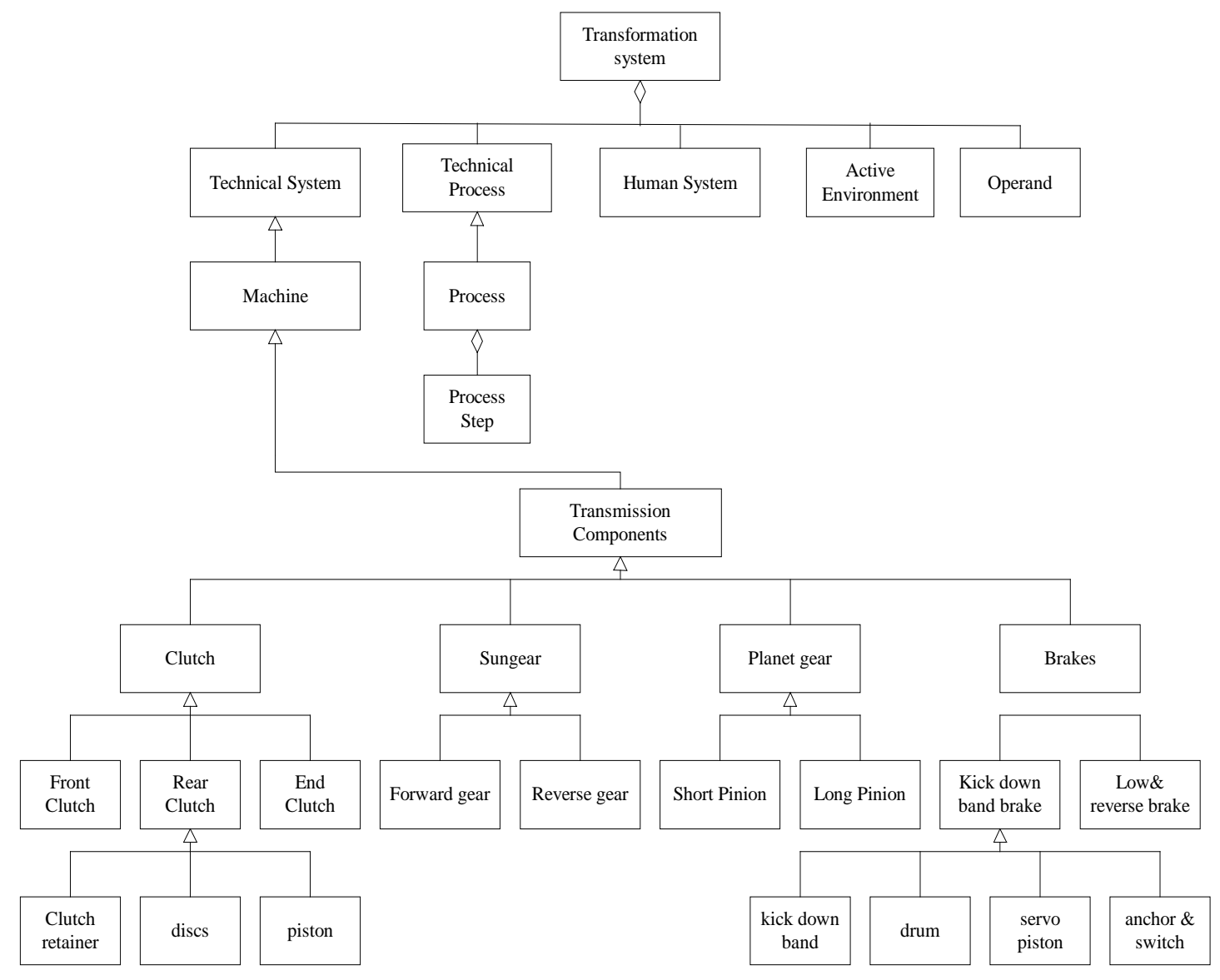

Figure 4. Object Diagram for the Transformation System 


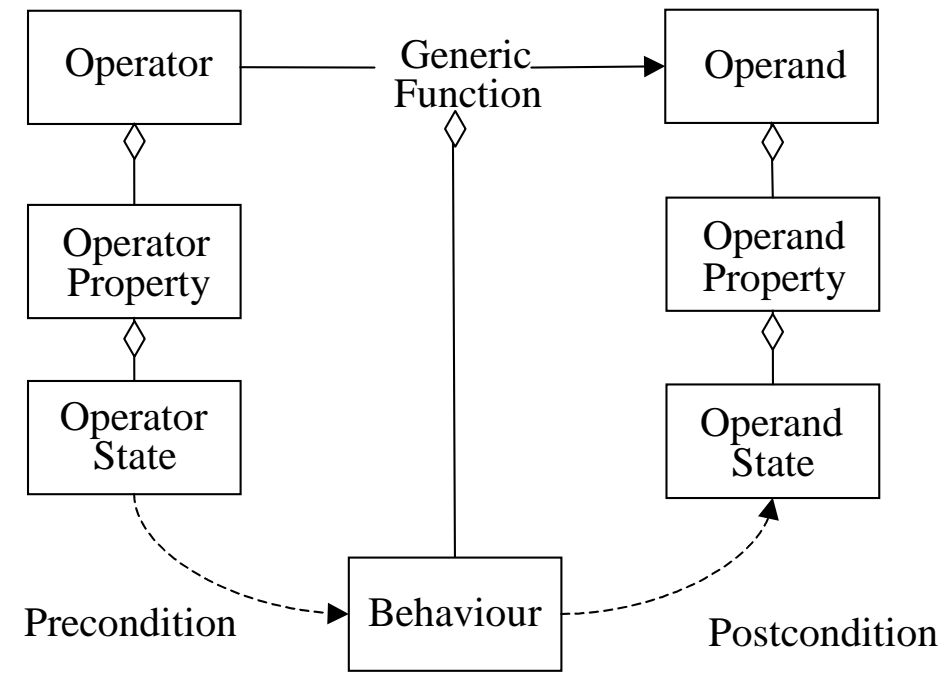

Figure 5. Precondition and Postcondition Relationship (based on Teoh, 2003) 


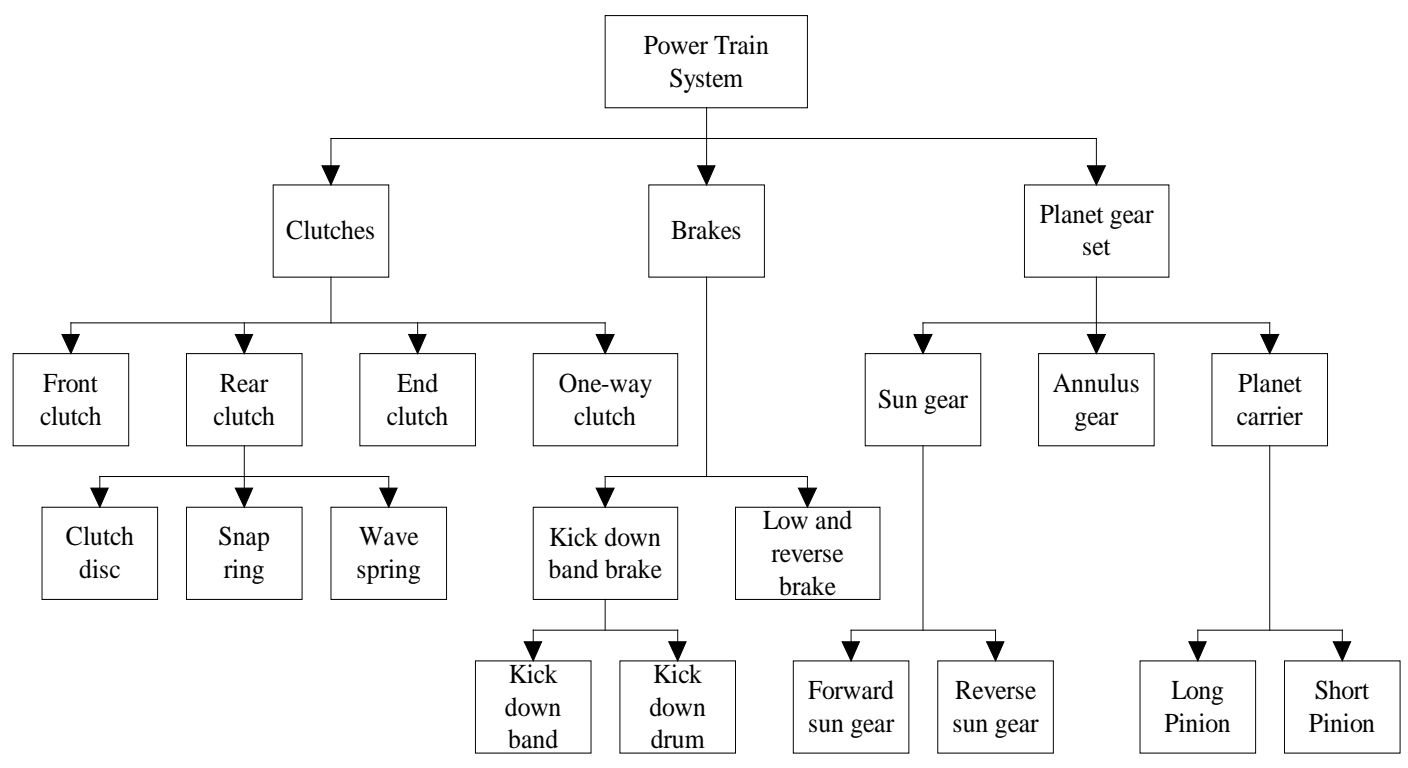

Figure 6. Structural Decomposition of Power Train System 


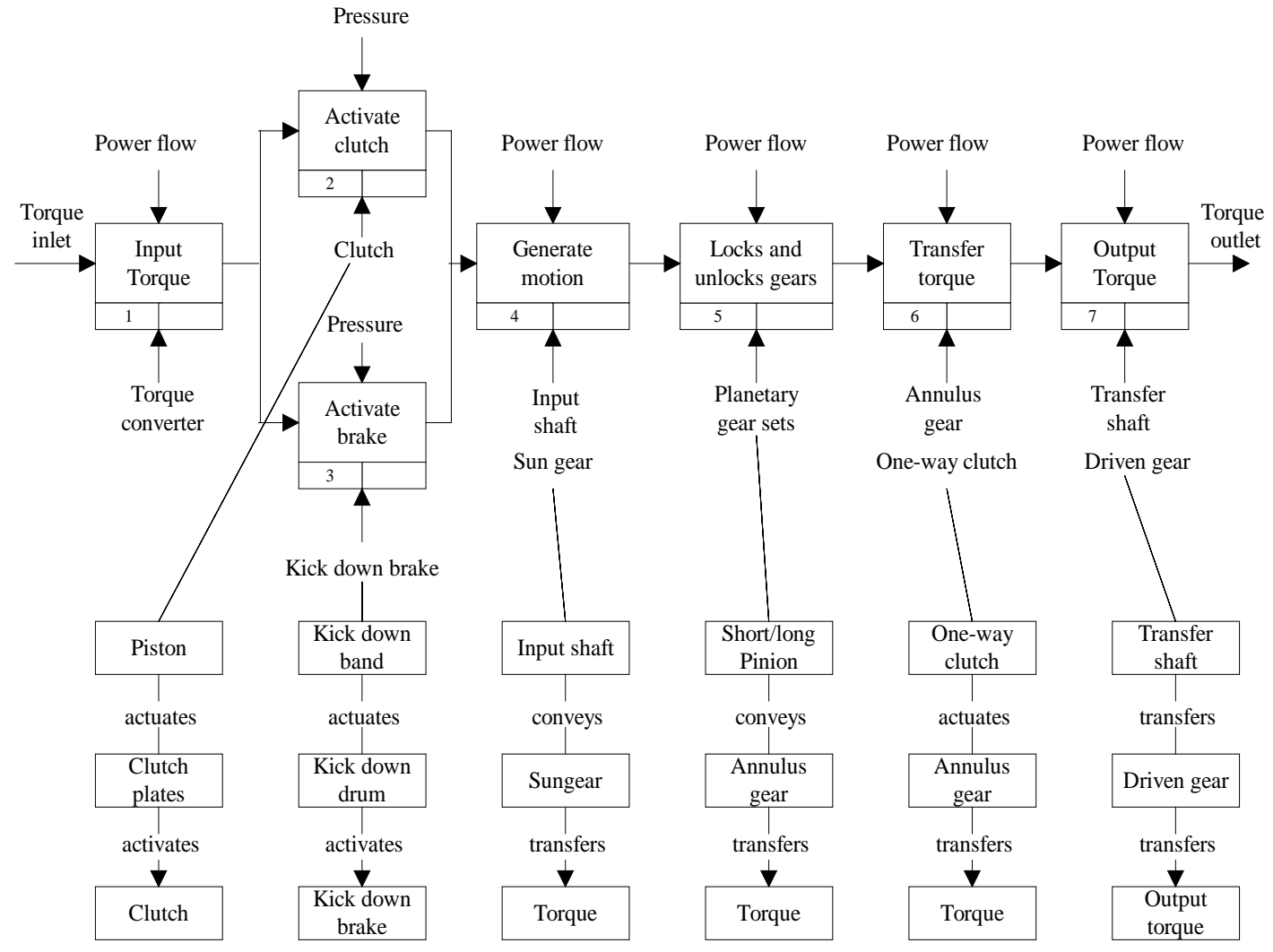

Figure 7. Function and Structure Mapping (Based on FMAG Approach, Teoh 2003) 


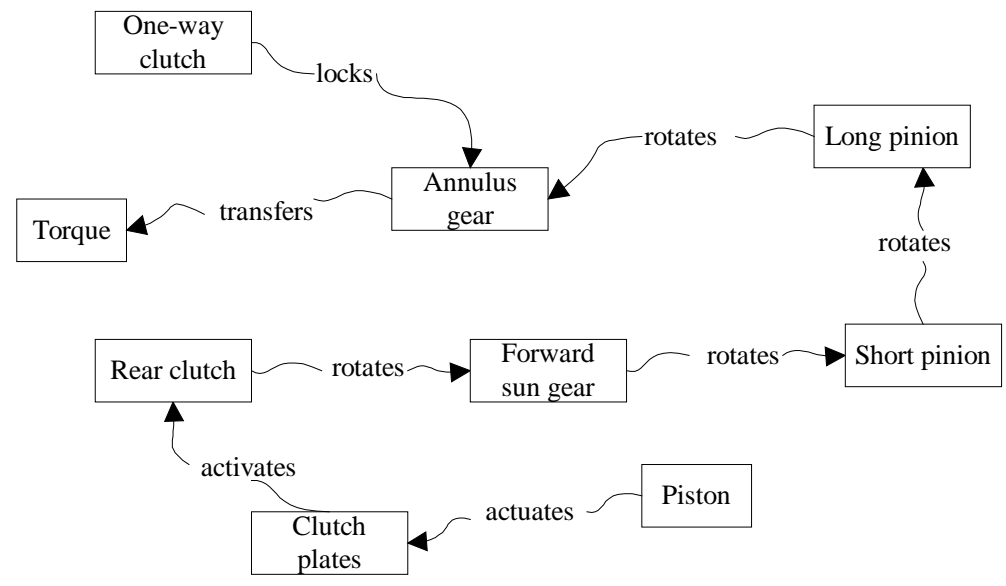

Figure 8. Functional Diagrams for $1^{\text {st }}$ Gear (D, 2, L range) 


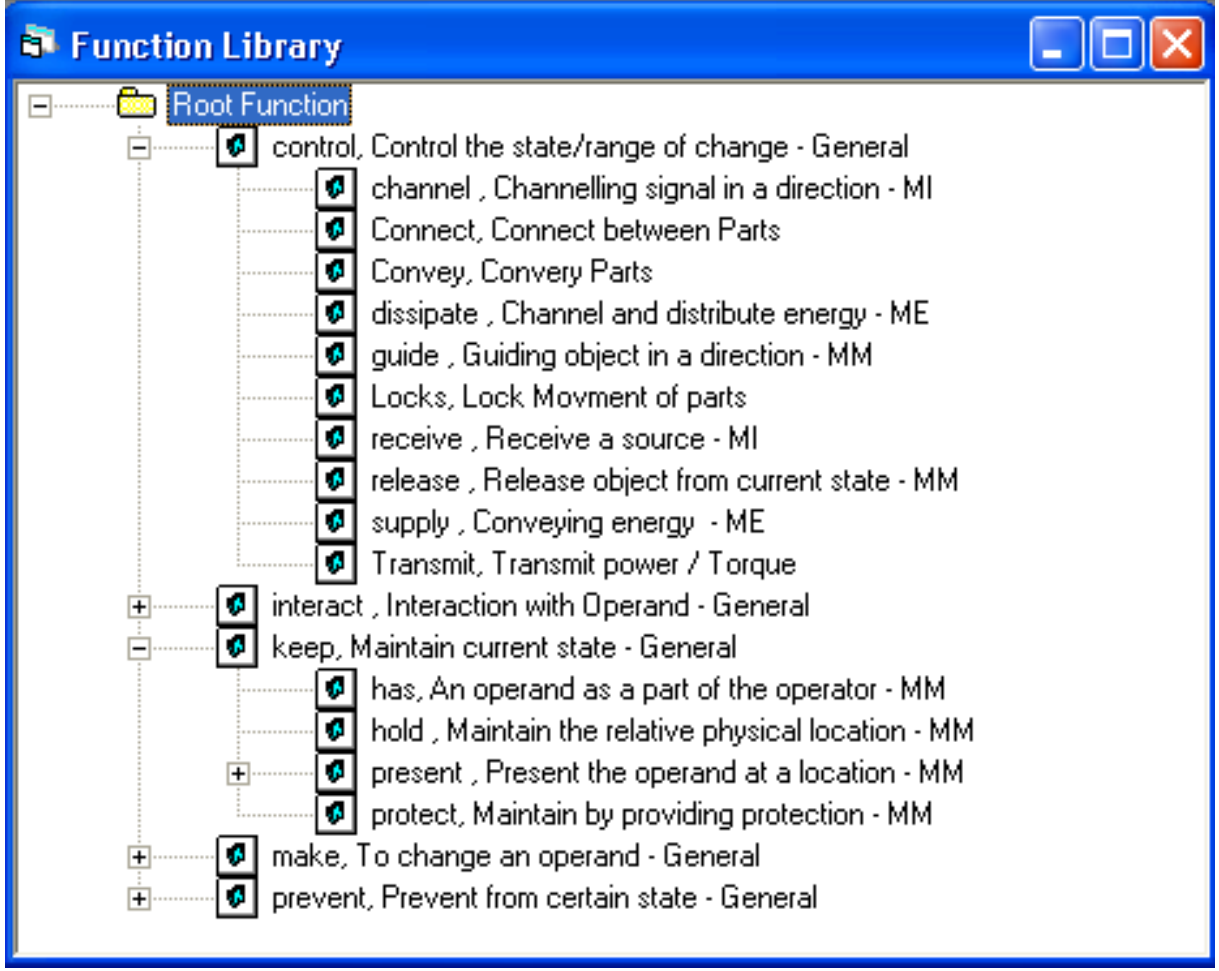

Figure 9. Function Library 


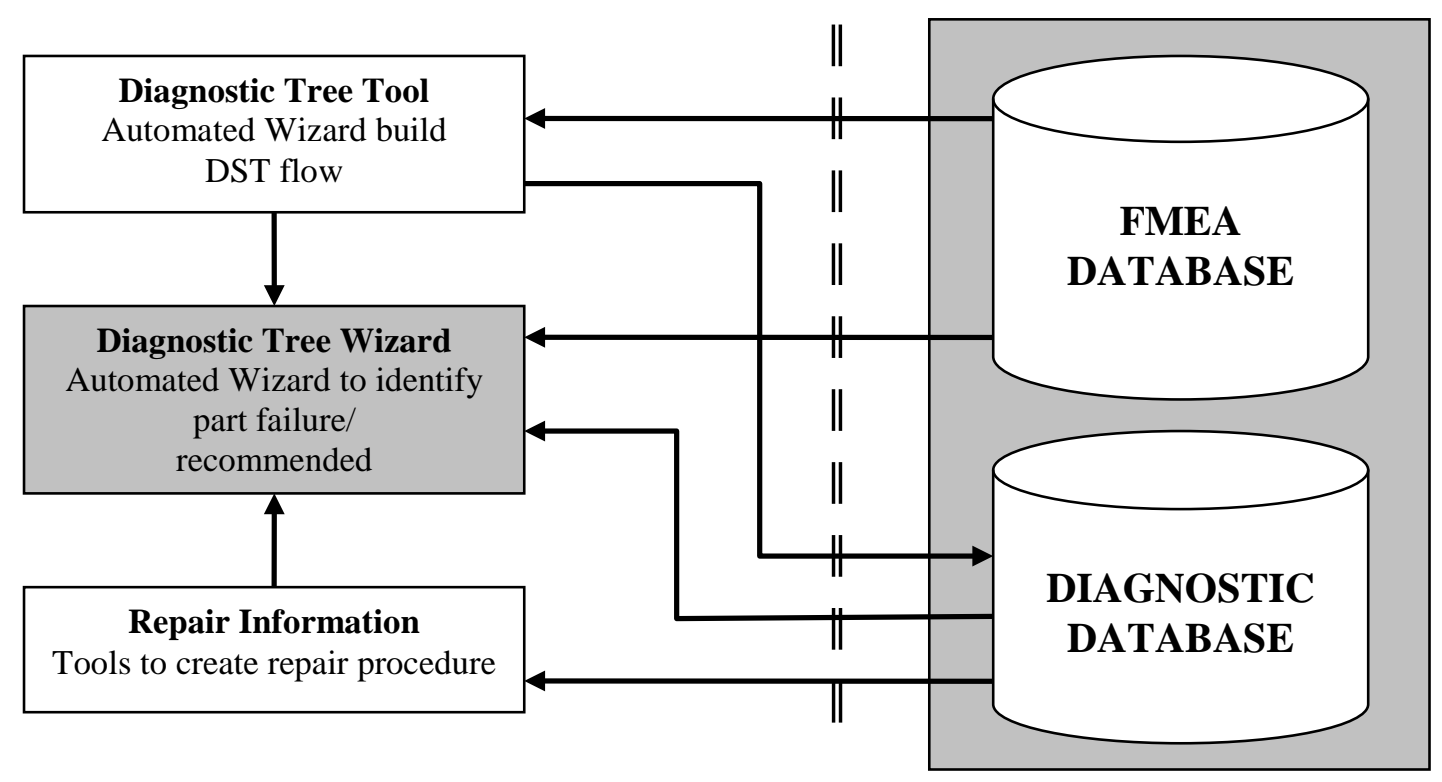

Figure 10. DST Application Structure 


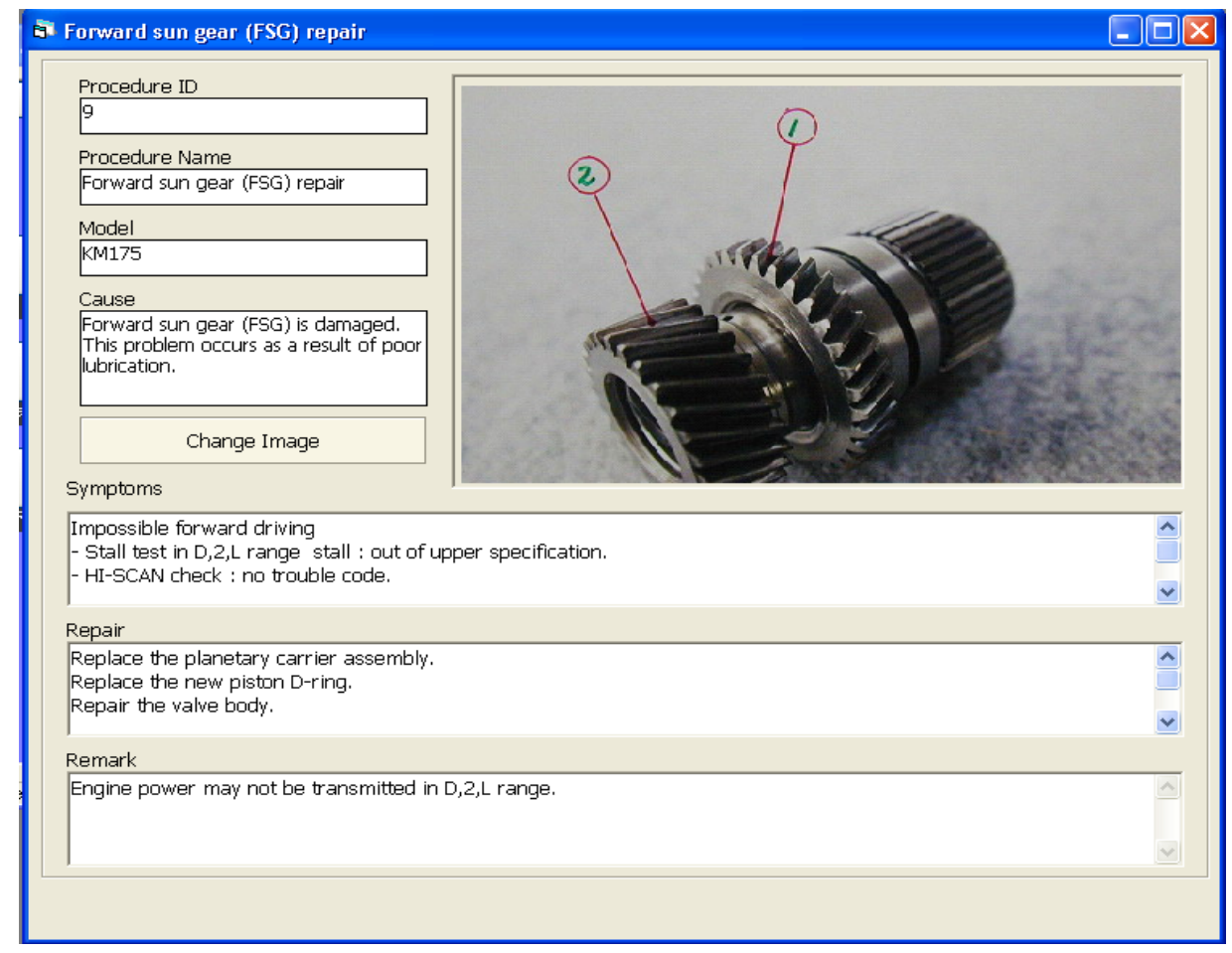

Figure 11. Repair Procedure for Sun Gear 


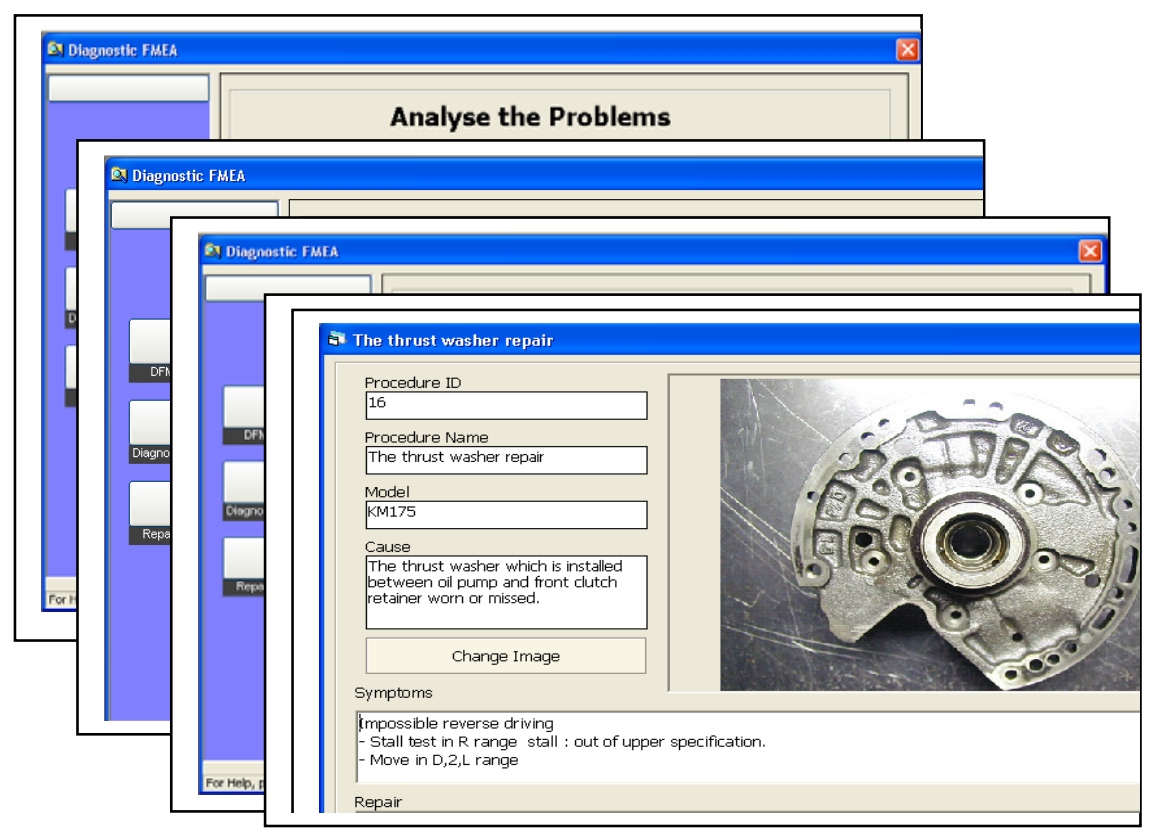

Figure 12. Transmission Problem Causes Analysis and Recommended Action

Table 1. Generic Functions (Teoh, 2003) 


\begin{tabular}{|c|c|c|c|}
\hline Class & Active & Passive & Description \\
\hline \multirow[t]{5}{*}{ Branch } & separates & separated from & $\begin{array}{l}\text { to separate an operand into components in the forms which } \\
\text { are distinct from the original }\end{array}$ \\
\hline & divides & divided from & $\begin{array}{l}\text { to separate an operand into components in the same form } \\
\text { as the original operand }\end{array}$ \\
\hline & extracts & extracted from & to forcefully pull out \\
\hline & removes & removed from & to take away a part of operand from the original \\
\hline & distributes & distributed to & to cause operand to break up \\
\hline \multirow[t]{10}{*}{ Channel } & inputs & input to & to bring an operand from outside into the system \\
\hline & outputs & output from & to send an operand from the system out \\
\hline & carries & carried to & $\begin{array}{l}\text { to carry and move together with an operand from one place } \\
\text { to another }\end{array}$ \\
\hline & transports & transported to & to move a material from one place to another (no fixed path) \\
\hline & transmits & transmitted to & $\begin{array}{l}\text { to move energy or signal from one place to another (no } \\
\text { fixed path) }\end{array}$ \\
\hline & guides & guided to & to direct a material with specific path \\
\hline & conducts & conducted to & to direct signal or energy with specific path \\
\hline & conveys & conveyed to & to fix the movement in linear direction \\
\hline & rotates & rotated to & to fix the movement around an axis \\
\hline & constrains & constraint to & to constrain the movement into a few DOF \\
\hline \multirow[t]{4}{*}{ Connect } & joins & joint to & $\begin{array}{l}\text { to bring together two or more operands, but they can still be } \\
\text { distinguished from each other }\end{array}$ \\
\hline & assembles & assembled to & to join with a predetermined manner \\
\hline & links & linked to & $\begin{array}{l}\text { to couple two or more operands with an intermediate } \\
\text { operand }\end{array}$ \\
\hline & mixes & mixed with & to combine two operands into a single homogeneous mass \\
\hline \multirow[t]{13}{*}{$\begin{array}{l}\text { Control } \\
\text { Magnitude }\end{array}$} & actuates & & $\begin{array}{l}\text { to enable an operand to commence an action based on a } \\
\text { control signal }\end{array}$ \\
\hline & regulates & & to adjust the operand based on a control signal \\
\hline & increases & & to enlarge an operand in response to a control signal \\
\hline & decreases & & to reduce an operand in response to a control signal \\
\hline & changes & & to adjust the operand in a predetermined manner \\
\hline & amplifies & & to enlarge an operand in a predetermined manner \\
\hline & reduces & & to reduce an operand in a predetermined manner \\
\hline & shapes & & to mould or form an operand \\
\hline & conditions & & to render an operand appropriate for the desired use \\
\hline & stops & & to cease an action of an operand \\
\hline & prevents & prevented from & to keep the operand from happening \\
\hline & shields & shielded from & $\begin{array}{l}\text { to restrain an operand, a portion of operand is till continue } \\
\text { to transfer }\end{array}$ \\
\hline & protects & protected from & to protect the operand from something \\
\hline Convert & generates & generated to & to change from one form to another \\
\hline \multirow[t]{4}{*}{ Provision } & stores & stored to & to accumulate an operand \\
\hline & contains & contained in & to keep an operand within limits \\
\hline & collects & collected to & to bring operands together \\
\hline & supplies & supplied to & to provide an operand from storage \\
\hline \multirow[t]{7}{*}{ Signal } & senses & sensed by & to become aware of an operand \\
\hline & recognise & recognised by & to identify an operand \\
\hline & measures & & to determine the magnitude of an operand \\
\hline & indicates & indicated to & to make known about an operand \\
\hline & tracks & & to observe and record data from an operand \\
\hline & displays & & to reveal something about the operand \\
\hline & processes & & to submit information for a process \\
\hline \multirow[t]{3}{*}{ Support } & stabilizes & & to prevent an operand from changing course or location \\
\hline & secures & secured to & to firmly fix an operand \\
\hline & positions & positioned to & to hold an operand in a specified location \\
\hline \multirow{2}{*}{$\begin{array}{l}\text { Non Standard } \\
\text { Function }\end{array}$} & interacts with & & to provide an effect through an interaction with the operand \\
\hline & forms & & to contribute to the formation of a new operand \\
\hline
\end{tabular}


Table 2. Precondition

\begin{tabular}{|c|c|c|}
\hline $\begin{array}{l}\text { Operator } \\
\text { Torque converter } \\
\text { Clutches \& brakes }\end{array}$ & $\begin{array}{l}\text { Generic Function } \\
\text { transfers } \\
\text { conveys }\end{array}$ & $\begin{array}{l}\text { Precol } \\
\text { conver }\end{array}$ \\
\hline
\end{tabular}

Table 3. Postcondition

\begin{tabular}{|c|c|c|}
\hline $\begin{array}{l}\text { Generic Function } \\
\text { Transfers }\end{array}$ & $\begin{array}{l}\text { Operand } \\
\text { Input shaft }\end{array}$ & Postcondition \\
\hline Conveys & Torque & not conveying - torque not conveying \\
\hline
\end{tabular}

